Revista de Filosofía y Teoría Política, n. ${ }^{\circ}$ 49, 2018, e018, ISSN 2314-2553 Universidad Nacional de La Plata.

Facultad de Humanidades y Ciencias de la Educación.

Departamento de Filosofía

\title{
Vulnerabilidad y resistencia. En busca de una "democracia radical y plural" en la obra de J. Butler
}

\author{
Malena Nijensohn \\ Instituto Interdisciplinario de Estudios de Género - CONICET, \\ Argentina \\ malenanijensohn@gmail.com
}

Cita sugerida: Nijensohn, M. (2018). Vulnerabilidad y resistencia. En busca de una "democracia radical y plural" en la obra de J. Butler. Revista de Filosofía y Teoría Política, (49), e018. https://doi.org/10.24215/23142553e018

Recibido: 06 septiembre 2017 - Aceptado: 16 febrero 2018 - Publicado: 01 noviembre 2018

(c) (1) (2) Esta obra está bajo licencia Creative Commons Atribución-NoComercial-CompartirIgual 4.0 Internacional (c) ${ }_{\text {BY }}$ Na SA $_{\text {SA }}$ http://creativecommons.org/licenses/by-nc-sa/4.0/deed.es_AR 


\section{Vulnerabilidad y resistencia. En busca de una "democracia radical y plural” en la obra de J. Butler}

Vulnerability and resistance. In search of a "radical and plural democracy" in Judith Butler's work

Malena Nijensohn

Instituto Interdisciplinario de Estudios de Género-CONICET, Argentina

malenanijensohn@gmail.com

\section{Resumen:}

En el artículo me propongo analizar la noción de "resistencia" en la obra de Judith Butler, para examinar cómo la autora fue complejizando su teoría y sus reflexiones. Parto del concepto de "subversión performativa", fundamental en sus primeras obras, para luego vincular la performatividad con la precariedad y llegar así a una teoría performativa de la asamblea. Anima este trabajo el objetivo de repensar formas de resistencia que radicalicen y pluralicen la democracia, en el sentido que Ernesto Laclau y Chantal Mouffe le han dado al concepto de democracia radical y plural.

Palabras Clave: Resistencia, Performatividad, Precariedad, Democracia.

\section{ABstract:}

In the article, I seek to analyse the notion of "resistance" in Judith Butler's work, to examine how the author has deepen her own theory and reflexions. I begin with the concept of "performative subversion", fundamental in her first works, and then I connect performativity and precarity to finally develop a performative theory of assembly. This article aims at rethinking ways of resistance that radicalise and pluralise democracy, in the meaning that Ernesto Laclau and Chantal Mouffe gave to the concept of "radical and plural democracy".

KEYWORDS: Resistance, Performativity, Precarity, Democracy.

Una de las críticas más recurrentes a la filosofía y a la teoría rotulada como "postmoderna”, ${ }^{1}$ que aquí llamaremos "postnietzscheana", ${ }^{2}$ es el riesgo de caer en un nihilismo tal, que ya no habría capacidad de acción por parte de los sujetos políticos. Así, cualquier crítica a la noción moderna de sujeto pondría en riesgo la política. Por caso, cuando Judith Butler abre su libro Gender Trouble (Butler, 1990) en 1990 efectuando una crítica a las "mujeres" como "sujeto del feminismo", surge una ola de miedos y reticencias dentro del feminismo, en la medida en que se lee la propuesta butleriana como una forma de deshacerse del sujeto "mujeres", como si lo estuviera rechazando sin más. Esto generó la pregunta por la posibilidad de pensar el feminismo y sus prácticas sin tal sujeto. ${ }^{3}$ Afortunadamente, esta lectura crítica de Butler no tuvo tanta repercusión como la recepción más positiva, es decir, aquella recepción entusiasta con las posibilidades que se abrían para pensar en un feminismo que no se redujera a un feminismo mainstream, blanco, heterosexual, de clase media y que pudiera incluir la disidencia sexual, el feminismo negro, la transexualidad y lo queer, entre otros.

Sin embargo, la pregunta por la capacidad de agencia y, sobre todo, por las posibilidades de resistencia quedó abierta, pues estas son dos cuestiones centrales si se quiere pensar la agencia política dentro de un marco teórico deconstructivo en el cual nociones como autonomía, libertad e independencia han perdido su carácter fundamental. Así, si se considera con Foucault que el sujeto está, justamente, sujetado, es decir que depende de las relaciones de poder que lo constituyen, surge la siguiente pregunta: è posible que un sujeto transforme aquellas relaciones de poder sin las cuales no llegaría a existir? Mi respuesta o, mejor dicho, mi 
apuesta, es que sí. Cómo, en qué medida y con qué alcances y limitaciones son las cuestiones que intentaré responder en el presente artículo.

Partiré de la teoría temprana de Judith Butler (Butler, 2007, 2010a, 2009a, 2010b) para analizar la noción de subversión que la autora propone en torno a la constitución de subjetividades sexo-generizadas y para desarrollar una noción de "agencia" que no se ancle en la concepción moderna del sujeto como sustancia, sino que contemple sus condicionamientos y limitaciones. Mostraré que una teoría de la performatividad puede zanjar el debate entre voluntarismo y determinismo y así dar lugar a una noción relacional de la subjetividad. Entender el género como una construcción performativa significa que no hay una sustancia previa a las expresiones de género y de la cual éstas dependan, sino que, por el contrario, el género se construye en cada palabra, acto, gesto y estilo performativos. Los actos performativos funcionan así como prácticas rituales y repetitivas que nos producen como sujetos sexuados y generizados. Cada reiteración del género abre un espacio que tiene el potencial de resignificar la norma reguladora y disciplinaria, operando siempre un corrimiento respecto de ella: en cada iteración performativa, el sexo es a un tiempo producido y desestabilizado. ${ }^{4}$

Ahora bien, ¿cómo es que la propia Judith Butler va complejizando su teoría y sus reflexiones hasta llegar a una teoría performativa de la asamblea? ¿Hay algo más que la iteración performativa de las normas establecidas o, mejor dicho, puede la teoría butleriana de la performatividad abordar nuevas aristas, trabajar nuevos temas y problemas y así, finalmente, reelaborarse y ampliarse?

En Cuerpos aliados y lucha política (Butler, 2017), Butler analiza la dimensión creativa de la acción plural a través de los procesos asamblearios que emergieron en distintas ciudades del mundo en los últimos años. Vinculando la performatividad y la precariedad, la estadounidense construye un escenario teórico que permite dar cuenta de ciertos procesos de resistencia en la democracia actual. En esa línea, no comprende la precariedad como un antónimo de la resistencia sino, por el contrario, como un concepto político que justamente da lugar a la agencia. Es por ello que en la segunda sección de este trabajo me centraré en sus últimos textos (Butler, 2009b, 2010c, 2017) para repensar formas de resistencia que radicalicen y pluralicen la democracia, en el sentido que Ernesto Laclau y Chantal Mouffe le han dado al concepto de democracia radical y plural, para que la distribución diferencial de precaridad sea un poco menos desigual y la cohabitación no sea un mero ideal.

\section{LA RESISTENCIA COMO SUBVERSIÓN A TRAVÉS DE LA ITERACIÓN DE LA CITA}

Para comprender la idea de Judith Butler de la resistencia como subversión de las normas establecidas es menester remontarse a su teoría de la constitución de la subjetividad, es decir, a la teoría de la performatividad. Es por ello que daremos un rodeo por los desarrollos butlerianos acerca de la formación discursiva de la identidad para luego adentrarnos específicamente en su concepción de la subversión.

\section{A) La formación discursiva de la identidad}

Judith Butler inicia su libro El género en disputa discutiendo con el feminismo que la antecede y poniendo en cuestión una idea que hasta ese entonces contaba con una aceptación generalizada dentro del movimiento, a saber: la idea de que hay un sujeto del feminismo, las mujeres, y que la lucha feminista está dirigida a lograr una mayor representación de las mujeres en el campo de la política para lograr su emancipación. Sin embargo, para Butler, esta concepción del feminismo conlleva una serie de problemas. En primer lugar, la categoría "mujeres" no es una categoría cerrada sino, por el contrario, "un sitio problemático, un lugar de refutación, un motivo de angustia” (Butler, 2007, p. 49). 
No basta con investigar de qué forma las mujeres pueden estar representadas de manera más precisa en el lenguaje y la política. La crítica feminista también debería comprender que las mismas estructuras de poder mediante las cuales se pretende la emancipación crean y limitan la categoría de "las mujeres", sujeto del feminismo. (Butler, 2007, p. 48)

Si el feminismo se limita a presuponer una universalidad, una unidad y una estabilidad del sujeto "mujeres", trabaja entonces con una construcción que se torna coactiva y reguladora, y de esta forma genera múltiples rechazos y exclusiones. ${ }^{5}$ Para Butler, si el feminismo no se hace cargo de sus propios movimientos excluyentes, por más emancipador que se pretenda, puede terminar teniendo el mismo tipo de efectos totalizantes que una posición heteronormativa. "La crítica feminista debe explicar las afirmaciones totalizadoras de una economía significante masculinista, pero también debe ser autocrítica respecto de las acciones totalizadoras del feminismo." (Butler, 2007, p. 66)

Así, al no cuestionar sobre qué exclusiones se funda el concepto "mujeres", el feminismo naturaliza ciertos presupuestos de raza y clase, presupuestos biológicos, económicos, culturales, etc. y constituye a las "mujeres" como aquellas determinadas por su cuerpo (aunque no quede claro si se refiere a las hormonas, la genitalidad, el útero o los caracteres secundarios), blancas, heterosexuales, de clase media. Esto genera que múltiples subjetividades (transexuales, lesbianas, negras, pobres, trabajadoras sexuales, etc.) queden excluidas del ideal emancipatorio feminista.

Mi intención aquí es argüir que las limitaciones del discurso de representación en el que participa el sujeto del feminismo socavan sus supuestas universalidad y unidad. De hecho, la reiteración prematura en un sujeto estable del feminismo entendido como una categoría inconsútil de mujeres - provoca inevitablemente un gran rechazo para admitir la categoría. Estos campos de exclusión ponen de manifiesto las consecuencias coercitivas y reguladoras de esa construcción, aunque ésta se haya llevado a cabo con fines objetivos de emancipación. (Butler, 2007, p. 51)

Esto no es casual, pues retomar el concepto "mujeres" de forma acrítica implica, de una forma u otra, aceptar la matriz heterosexual, en la medida en que "mujeres" sólo cobra sentido al interior de esa matriz. Como sostiene Monique Wittig (Wittig, 2006), “no existen mujeres sin hombres” (p. 22), porque la noción de mujer ("la categoría de sexo") no existe como un a priori o independientemente de una sociedad dada, sino que es una categoría política; más aún, es la categoría política que funda la sociedad como heterosexual. Que la sociedad se funda como heterosexual significa que se considera a la relación heterosexual como un núcleo natural que resiste el cuestionamiento. Así se constituye, a los ojos de Wittig, el "pensamiento heterosexual”, aquella dominación no sólo simbólica sino también material por la cual los varones se apropian de la reproducción y la producción de las mujeres y de ellas en tanto personas físicas a través del contrato matrimonial. En este sentido, sostiene Wittig (Wittig, 2006) que "las lesbianas no son mujeres" (p. 57) en la medida en que, y el punto central que nos interesa, “la-mujer' no tiene sentido más que en los sistemas heterosexuales de pensamiento y en los sistemas económicos heterosexuales” (p. 57). Butler (Butler, 2007) retoma esta concepción de Wittig y sostiene:

Quizás el problema sea todavía más grave. La construcción de la categoría de las mujeres como sujeto coherente y estable, ¿es una reglamentación y una reificación involuntaria de las relaciones entre los géneros? ¿Y no contradice tal reificación los objetivos feministas? (Butler, 2007, p. 52)

El blanco de la crítica butleriana es la presunción de que el término "mujeres" indica algo así como una identidad común previa a los mecanismos discursivos de representación, pues para ella, siguiendo a Michel Foucault, las relaciones de poder producen a los sujetos que más tarde representan. Se advierte así que no hay una identidad sustancial que luego es representada discursivamente sino que, por el contrario, son esos discursos (el heteronormativo, pero asimismo y quizás sin darse cuenta el feminista clásico también) los que producen, en este caso, la categoría "mujeres". La posición butleriana antifundacionalista con respecto a las coaliciones políticas asume que la "identidad" no puede ser una premisa. Es decir que este nuevo feminismo propone interrogar las prácticas reguladoras de la formación del género y analizar cómo éstas constituyen las identidades y la supuesta coherencia interna de los sujetos. 
A este respecto, consideramos clave la herencia de Friedrich Nietzsche (que a Butler le llega a través de los autores franceses postestructuralistas, como Michel Foucault y Jacques Derrida), pues la crítica a la metafísica de la sustancia será la (des)base ontológica para repensar la cuestión de la subjetividad desde una perspectiva que deseche concepciones sustancialistas y la ilusión de que hay un sujeto ya constituido, previo a las acciones que realiza. $^{6}$

La identidad sexo-genérica, tal como es producida por la matriz de inteligibilidad de la heterosexualidad obligatoria, pretende que haya un vínculo causal que va desde el sexo (en tanto que dato biológico: macho/ hembra) hacia el género (como producción cultural de feminidad y masculinidad) y finalmente hacia el deseo (heterosexual). En sentido contrario, el deseo será la expresión del género y el género la expresión del sexo. La institución heterosexual requiere y produce a un tiempo la univocidad de cada uno de estos términos dentro de un sistema oposicional binario: macho/hembra, varón/mujer, práctica heterosexual bajo la ley de complementariedad de los sexos.

Butler se propone desplazar esa relación binaria que responde a la metafísica de la sustancia para poder pensar que esas categorías no son naturales sino, muy por el contrario, producidas.

Si la noción de una sustancia constante es una construcción ficticia creada a través del ordenamiento obligatorio de atributos en secuencias coherentes de género, entonces parece que el género como sustancia, la viabilidad de hombre y mujer como sustantivos, se cuestiona por el juego disonante de atributos que no se corresponden con modelos consecutivos o causales de inteligibilidad. (Butler, 2007, p. 83)

El efecto sustantivo del género no es una realidad pre-existente sino que es producido por el régimen regulatorio heteronormativo. Entonces, si el género no es una sustancia, ¿qué es? El género resulta ser performativo, dirá J. Butler, en la medida en que produce la identidad que se supone que es. En ese sentido, "no existe una identidad de género detrás de las expresiones de género; esa identidad se construye performativamente por las mismas 'expresiones' que, al parecer, son el resultado de ésta." (Butler, 2007, p. 85) Cada palabra, acto, gesto y estilos performativos constituyen la identidad, produciendo la apariencia de sustancialidad. Así, cuando el médico dice "es un niño" o "es una niña”, no está haciendo una mera descripción neutral de la anatomía de los bebés, sino que los está nombrando y, en el mismo momento en que lo hace, los está formando y los está inscribiendo en un circuito (y normas) de reconocimiento. Así, se pone en marcha una cadena de repeticiones, rituales, citaciones e invocaciones que irán configurando la identidad masculina o femenina. Es en este sentido que el performativo funciona como una práctica ritual repetitiva que nos produce como sujetos sexuados y generizados. Nuestra identidad es instituida por una repetición estilizada de tales actos. Cada vez que citamos una norma de género, estamos citando el régimen regulatorio y disciplinario del género y estamos constituyendo performativamente nuestra identidad a través de sus normas.

\section{B) Estrategias de desplazamiento: la resistencia como subversión}

Siguiendo a Michel Foucault, Butler sostiene que, si sexualidad y poder son coextensivos, entonces hay que refutar el postulado de una sexualidad subversiva o emancipadora que podría liberarse de aquella ley que, justamente, la produce. Es decir, si la sexualidad, así como el gé nero o, estrictamente hablando, la subjetividad sexo-generizada, es producida por las relaciones de poder existentes, entonces no podemos seguir pensando en una resistencia cuya modalidad sea la de situarse "antes", "por fuera" o "más allá" de la ley.

Si la sexualidad se construye culturalmente dentro de las relaciones de poder existentes, entonces la pretensión de una sexualidad normativa que est "antes", "fuera" o "más allá" del poder es una imposibilidad cultural y un deseo políticamente impracticable, que posterga la tarea concreta y contemporánea de proponer alternativas subversivas de la sexualidad y la identidad dentro de los trminos del poder en sí. (Butler, 2007, p. 94) 
Sin embargo, repensar las posibilidades subversivas de la sexualidad y de la identidad dentro de los términos del poder no significa repetir las relaciones de dominación sin un sentido crítico. De hecho, se trata de pensar en la posibilidad de una repetición de la ley que no sirva a su consolidación sino a su desplazamiento. Esto se debe a que en la concepción butleriana no puede haber un repudio radical de los constructos culturales, en el sentido de un lugar del "Gran Rechazo" (Foucault, 2005, p. 116), dado que las normas que gobiernan la inteligibilidad del género son las que permiten la constitución de la subjetividad.

Si dichas normas operan a través de la repetición, ¿puede haber, entonces, formas de repetición que no sean la mera reproducción y por tanto la consolidación de la ley que gobierna la vida sexo-generizada? Según Butler, la repetición de los constructos heterosexuales puede ser al mismo tiempo la ocasión para su desnaturalización y la movilización de las categorías genéricas. La repetición paródica llevada a cabo, por ejemplo, en la práctica drag, de cross-dressing, o en las identidades butch y femme, no es sólo una parodia del estereotipo de género, sino que es, estrictamente, la repetición paródica de la noción de una identidad de género original o primaria. Así, la parodia revela que el original no es sino ya una parodia de sí mismo. En ese sentido, cae la dicotomía entre original y copia, pues nos encontramos frente a la copia de la copia de la copia.

Butler toma aquí el caso de la drag para mostrar que, al imitar el género, implícitamente lo que hace es dar cuenta de la estructura imitativa de toda performance de género. La identidad supuestamente original a través de la cual las "mujeres" se convierten en "mujeres" y los "varones" en "varones”, por caso, ya es una imitación, pero una imitación sin original: una producción que se posiciona como imitación. Así, determinadas configuraciones de género pueden ser el lugar de la intervención, la exposición y el desplazamiento de las leyes regulatorias del género.

El hecho de que los regímenes de poder del heterosexismo y el falogocentrismo adquieran importancia mediante una repetición constante de su lógica, su metafísica y sus ontologías naturalizadas no significa que deba detenerse la repetición en sí -como si esto fuera posible-. Si la repetición debe seguir siendo el mecanismo de la reproducción cultural de las identidades, entonces se plantea una pregunta fundamental: ¿qué tipo de repetición subversiva podría cuestionar la práctica reglamentadora de la identidad en sí? (Butler, 2007, p. 96)

La propuesta butleriana es, hasta aquí por lo menos, una apuesta por la subversión a través del desplazamiento de las nociones naturalizadas del género, que son las que a su vez sostienen el régimen heteronormativo. Se trata de poner "el género en disputa" ("make gender trouble") a través de una repetición que no es una reificación sino, muy por el contrario, una transformación de las normas reguladoras del género. Si la acción del género requiere de una performance que es repetida, es en esa repetición donde hallamos la ocasión de un desplazamiento, de la resignificación o de la recontextualización.

Las probabilidades de transformación del género radican precisamente en la relación arbitraria entre tales actos, en la opción de no poder repetir, una de-formidad o una repetición paródica que demuestra que el efecto fantasmático de la identidad constante es una construcción políticamente insuficiente. (Butler, 2007, p. 274)

En Cuerpos que importan, Judith Butler indaga los procesos de materialización de los cuerpos y sostiene que el "sexo", lejos de ser algo natural (como hemos indicado más arriba), es parte de una práctica reguladora que produce los cuerpos que gobierna. En ese sentido, es un proceso a través del cual las normas reguladoras materializan el "sexo" a través de la reiteración forzada de las normas.

Los desarrollos butlerianos de Cuerpos que importan permiten profundizar ciertas ideas ya trabajadas en El género en disputa. Aquí vemos cómo la materialización, por no ser un acto único sino un proceso que se da en el tiempo, nunca se completa. Y es justamente en esas inestabilidades que se abren en el proceso que la ley reguladora puede volverse contra sí misma para generar rearticulaciones que pongan en cuestión la fuerza de dicha ley. Así, las normas reguladoras del "sexo" funcionan performativamente, constituyendo la materialidad de los cuerpos, materializando el sexo de los cuerpos, materializando la diferencia sexual al servicio de la heteronormatividad. La asunción de un sexo será entonces una asunción obligatoria, en el sentido de que 
estará regulada por la heterosexualidad obligatoria. Ahora bien, ¿podemos en este marco teórico pensar en algo así como una agencia?

Y si existe una libertad de acción ["agency"], ésta debe buscarse, paradójicamente, en las posibilidades que ofrecen la apropiación obligada de la ley reguladora, la materialización de esa ley, la apropiación impuesta y la identificación con tales demandas normativas. (Butler, 2010a, p. 33)

Al ser la materialización y la performatividad procesos y no actos singulares, es siempre en la reiteración de la(s) norma(s) donde encontraremos la ocasión de su resignificación o dislocación.

Si la "sujeción" es a un tiempo el proceso de devenir subordinado al poder y el proceso de devenir sujeto, es porque el sujeto se inicia mediante una sumisión primaria al poder (Butler, 2010b, p. 12). Así comolas normas hegemónicas deben ser reiteradas y, en ese sentido, conservadas y resignificadas, el poder o, mejor dicho, las relaciones de poder, son aquello que nos forma como sujetos, aquello de lo que dependemos para vivir al mismo tiempo que es aquello a lo que nos oponemos. Aquí cobra sentido la "paradoja del assujettissement" foucaultiana, a saber: que nadie deviene sujeto sin experimentar sujeción, que para convertirnos en sujetos tenemos que estar sujetados. Y la contrapartida es que, al oponerse a la subordinación, el sujeto está reiterando su sujeción. ¿Pero cómo es posible esta forma paradójica del poder? ¿Cómo puede la sujeción consistir en una dependencia fundamental de unas relaciones de poder que no elegimos y ser lo que inicia y sustancia nuestra agencia?

Butler (Butler 2010b) analiza esta forma paradójica del poder a través de la figura de darse la vuelta,

una vuelta sobre uno/a mismo/a o incluso contra uno/a mismo/a. Esta figura forma parte de la explicación de cómo se produce el sujeto, por lo cual, en sentido estricto, no existe un sujeto que se dé la vuelta. Por el contrario, la vuelta parece funcionar como inauguración tropológica del sujeto, como momento fundacional cuyo estatuto ontológico será siempre incierto. (Butler, 2010b, p. 13)

En este sentido, no hay un sujeto previamente existente que se dé la vuelta, sino que la vuelta inaugura al sujeto. Esta figura puede comprenderse gracias a la lectura butleriana de la interpelación en Althusser (Butler, 2009a, pp. 49-53). En la escena de la interpelación de Althusser, un policía se dirige hacia alguien que pasa y quien se reconoce se gira para responder a la llamada. Estrictamente hablando, quien se da vuelta no preexiste sino que justamente al girarse adquiere una determinada identidad, pues la llamada trae a este sujeto a la existencia, de forma tal que este acto de reconocimiento se convierte en un acto constituyente. ${ }^{7}$ En la lectura butleriana, esta escena permite dar cuenta de que el sujeto no es un agente soberano (pues precisa de una llamada para adquirir inteligibilidad) sin por eso ser un mero efecto de las relaciones de poder. Lo que vemos es una vulnerabilidad primaria, una dependencia de la llamada del otro para llegar a ser (volveré sobre la cuestión de la vulnerabilidad en la siguiente sección).

Un nombre es concedido, dado, impuesto o atribuido por alguien (o por un grupo de personas) a alguien; así, el nombre emerge como la forma en la cual uno se dirige a otro. Esta escena aparece en primer lugar como una acción unilateral, en la medida en que están quienes nombran a otros, quienes a través de una convención lingüística llaman a otros y establecen así el acto de nombrar. Sin embargo, esta acción aparentemente unilateral no es tal, pues quien nombra también ha sido nombrado y, por lo tanto, posicionado en el lenguaje como alguien que está sujeto a esa llamada inaugural. De esta forma, vemos que tal sujeto se posiciona en el lenguaje tanto como aquel que nombra y como aquel que es nombrado. La posibilidad de nombrar a otro requiere haber sido ya nombrado y aquel que es nombrado es también alguien que puede nombrar. El sujeto hablando está constantemente condicionado por la vulnerabilidad de la llamada constituyente.

Situado al mismo tiempo en tanto que hablante y oyente, demorándose en esa encrucijada del poder, el sujeto no sólo es fundado por el otro, necesitando de una llamada para existir, sino que además su poder proviene de la estructura de esa llamada que es al mismo tiempo vulnerabilidad lingüística y ejercicio. Si llegamos a existir por medio de la llamada, ¿podríamos imaginar un sujeto al margen de su condición lingüística? (Butler, 2009a, p. 57) 
$\mathrm{Al}$ ser llamado con un nombre, uno no sólo es fijado por ese nombre con el que es llamado, sino que el nombre contiene asimismo otra posibilidad: al ser llamado con nombre, se nos ofrece una cierta existencia social, se nos inicia en la vida temporal del lenguaje y aquí aparece el punto en el cual se puede exceder los propósitos iniciales que animaron la llamada. Volviendo a la figura de darse la vuelta y a la escena de la interpelación de Althusser, al girar el individuo no sólo está respondiendo a la llamada, sino que está ganando al mismo tiempo su subjetividad y, por tanto, su agencia (siempre condicionada por la llamada inaugural o, estrictamente hablando, por las múltiples llamadas inaugurales).

Butler retoma los desarrollos de Jacques Derrida en torno a la teoría de los actos de habla de John L. Austin. Para Derrida, el enunciado performativo surte su efecto en la medida en que su formulación repite un enunciado codificado, es decir, iterable. En ese sentido, cada enunciado no es sino una cita de enunciados pasados. Ahora bien, dado que cada iteración del enunciado se da en un contexto novedoso, dicha cita puede ser resignificada. En cada recontextualización se introduce un desplazamiento de sentido. De allí que la iteración sea a un tiempo repetición y alteración: la repetición de un enunciado es la ocasión para su alteración.

Así, un enunciado puede ser "devuelto" a quien lo pronunció de una forma diferente, puede ser citado en contra de su propósito original y puede suscitar una inversión (o un desplazamiento) de sus efectos. La performatividad discursiva es una cadena ritual de significaciones cuyo origen permanece perdido. Así, el "acto" performativo no es una acción única y determinada sino la condensación de la iterabilidad que excede el momento que la ocasiona. Justamente la posibilidad de resignificación depende del espacio entre el contexto por el cual un enunciado es proferido y los efectos que produce. En esa repetición que es resignificación se abre a posibilidad de la agencia.

Con respecto al "sexo", éste es asumido de la misma forma que un sujeto es nombrado y que la ley es citada. Citar la ley es el mecanismo a través del cual dicha ley se produce y articula. En la repetición, la ley halla su fortaleza y su idealización como ley y, al mismo tiempo, la grieta a través de la cual podrá ser dislocada. La ley debe repetirse para continuar siendo una ley autorizada, y es en esa repetición donde la ley reinstituye la posibilidad de su propio fracaso.

Cada vez que la ley es iterada, el "sexo" es producido y desestabilizado, puesto que el "sexo" o, mejor dicho, el sexo-género, si bien se constituye a través del régimen regulador y disciplinario gracias a la repetición performativa de la ley, no se repite necesariamente bajo la figura de la mismidad, sino que abre a la posibilidad de la diferencia.

Como un efecto sedimentado de una práctica reiterativa o ritual, el sexo adquiere su efecto naturalizado y, sin embargo, en virtud de esta misma reiteración se abren brechas y fisuras que representan inestabilidades constitutivas de tales construcciones, como aquello que escapa a la norma o que la rebasa, como aquello que no puede definirse ni fijarse completamente mediante la labor repetitiva de esa norma. (Butler, 2010a, p. 29)

El proceso es doble: por un lado, legitimación y autorización de las normas; por el otro, desestabilización y resignificación. Es en la reiteración de la norma, pensada como cadena de citas pasadas de poder, donde puede sobrevenir la resignificación o la diferencia respecto de aquéllas. Siguiendo este recorrido, lo que parecía una repetición irremediable del sometimiento, se muestra ahora como la condición misma de la resistencia: sólo porque la norma se reitera en el sujeto es que, sobre ella, como inacabada, puede sobrevenir la diferencia.

Así, la agencia sólo puede ser comprendida como condicionada por las relaciones de poder. "Aunque se trate de un poder que es ejercido sobre el sujeto, el sometimiento es al mismo tiempo un poder asumido por el sujeto, y esa asunción constituye el instrumento de su devenir." (Butler, 2010b, p. 22) ¿Nos encontramos entonces en un círculo vicioso en el cual cualquier intento de oponerse a la subordinación necesariamente la presupondrá y la reinvocará? Quizás. Pero esto no significa que estemos destinados a reinstituir las normas hegemónicas una y otra vez bajo la lógica del determinismo. Por el contrario, sostiene Judith Butler en Mecanismos psíquicos del poder, hay una discontinuidad entre el poder que se presupone y el poder que se reinstituye y el poder como condición del sujeto no es necesariamente lo mismo que el poder que el sujeto 
ejerce. Entre uno y otro, una inversión significativa y potencialmente habilitante da lugar a la agencia o, en otras palabras, a la resistencia dentro de las condiciones de la reiteración.

El proceso de asumir el poder no consiste sencillamente en cogerlo de un lado, transferirlo intacto y enseguida convertirlo en propio; el acto de apropiación puede conllevar una modificación tal que el poder asumido o apropiado acabe actuando en contra del poder que hizo posible esa asunción. (Butler, 2010b, p. 23)

Si comprendemos la asunción del poder como condicionada a la subordinación en una forma ambivalente, vemos que el poder puede al mismo tiempo retener y resistir dicha subordinación. El poder no sólo actúa sobre (acts on) el sujeto, sino que al mismo tiempo actúa (enacts) al sujeto. El sujeto es inaugurado a través de la inversión temporal en el horizonte del poder y se muestra ahora como un sitio de ambivalencia, puesto que emerge como el efecto de las relaciones de poder al mismo tiempo que la condición de posibilidad de la agencia (condicionada). Ningún sujeto emerge sin la intervención del poder, pero la agencia excede el poder que la habilita.

Hasta acá me enfoqué en la constitución de la subjetividad y en cómo la conceptualización butleriana permite abordar la problemática de la resistencia y la agencia, una vez deconstruido el sujeto moderno. Al reconocer al sujeto no como subjectum, ${ }^{8}$ sino como el efecto de las relaciones de poder, como el efecto performativo de la matriz heterosexual, los valores que antes se pretendían absolutos (libertad, voluntad, autonomía) ahora se muestran como relacionales, es decir, dependientes de, y condicionados por, las normas hegemónicas que habilitan al sujeto. El sujeto butleriano no está inscripto ni en la lógica esencialista del determinismo ni en la lógica constructivista del voluntarismo. Así, su capacidad de agencia no es abandonada, pero es concebida en términos relacionales y condicionados. Esta "limitación" (que a muchos autores críticos de la postmodernidad y a muchas feministas les ha dejado "sabor a poco") es, en mi lectura, la potencia de la teoría de Judith Butler: aunando en el mismo locus tanto la subordinación como el devenir sujeto, encuentra una posibilidad para pensar la agencia y la resistencia.

Como dice Leticia Sabsay (Sabsay, 2005),

\begin{abstract}
Este planteo nos deja saborear un bello horizonte: en efecto, aún en sus gestos más conservadores, la reproducción del orden social nunca será total, aun en los intentos más reaccionarios de mantener el orden de las cosas tal cual es, esto será imposible, porque la repetición del orden supone necesariamente su transformación. Pero su otra cara no nos evitará el sinsabor de la contrariedad: a su vez, todo intento de transformación social, aún en sus versiones más radicales, nunca podrá deshacerse completamente de las normas ya instituidas.
\end{abstract}

Este marco conceptual deja asentadas ciertas premisas respecto de las posibilidades de resistencia en la obra de Butler. Sin embargo, ella misma ha ido ampliando y reconceptualizando sus desarrollos. A partir de libros como Vida precaria y Marcos de guerra, la cuestión de la precariedad se vuelve el núcleo articulador de la problemática política de la transformación. Y si bien las coaliciones políticas en democracia ya habían aparecido en libros como El género en disputa (Butler, 2007, pp. 67-70), creo que la reflexión de Butler sobre la vinculación entre precariedad y performatividad desarrollada en su último libro, Cuerpos aliados y lucha política, permite abordar la problemática de la resistencia en la democracia actual de una forma más cabal. Es por ello que, en el próximo apartado, para analizar estos nudos conceptuales en la obra de Butler, también daré un rodeo por la teoría de la hegemonía de Ernesto Laclau y Chantal Mouffe. La pregunta que guiará la siguiente sección será: ¿hay un concepto de democracia radical y plural en Butler?

\title{
II. Precariedad y Performatividad: en bUSCA DE UNA PerformatividAD PLURAL
}

Las referencias de Butler a la "democracia radical y plural" aparecen ya en Cuerpos que importan, incluso en el artículo "Fundamentos contingentes...”. Sin embargo, considero que, en términos de desarrollos conceptuales, la potencia de la teoría de Laclau y Mouffe cobra todo su espesor en el últimbibro de Butler. Comenzar esta sección dedicándome a la teoría de la precari(e)dad butleriana para luego adentrarme en 
Hegemonía y estrategia socialista y, finalmente, analizar la relación entre precariedad y performatividad en los procesos políticos contemporáneos de constituciones asamblearias.

\section{A. Precari (e)dad}

En Vida precaria Judith Butler se pregunta qué forma debe tomar la reflexión política si tomamos la vulnerabilidad y la agresión como los dos puntos de partida de la vida política, es decir, si consideramos que nuestra vida depende de otros: otros a quienes en algunos casos conocemos pero tambin otros a quienes no conocemos y quizás nunca conozcamos. En el segundo de los ensayos recogidos en ese libro, titulado "Violencia, duelo, política", la autora se pregunta por "lo que cuenta como humano, las vidas que cuentan como vidas y, finalmente, lo que hace que una vida valga la pena." (Butler, 2009b, p. 46) En esta pregunta se halla implícita la premisa de que lo humano no es un atributo esencial de todos los seres humanos y que se trata más bien de un proceso de humanización o de deshumanización de determinadas vidas.

De algún modo, todos vivimos con esta particular vulnerabilidad, una vulnerabilidad ante el otro que es parte de la vida corporal, una vulnerabilidad ante esos súbitos accesos venidos de otra parte que no podemos prevenir. Sin embargo, esta vulnerabilidad se exacerba bajo ciertas condiciones sociales y políticas, especialmente cuando la violencia es una forma de vida y los medios de autodefensa son limitados. (Butler, 2009b, p. 55)

Aquí vemos entonces ya la idea de que, si bien la vulnerabilidad es una condición humana común, pues precede cualquier formación del "yo", algunas vidas humanas son más vulnerables que otras. Esta diferenciación se hace patente en el libro Marcos de guerra, en el que Butler distingue entre la precariousness, una condición de toda vida, y la precarity, que es distribuida desigualmente.

Ahora bien, ¿en qué sentido podemos decir que toda vida es una vida precaria? Si el cuerpo está siempre expuesto y abierto a los otros, a las normas, a la creación y formación social, entonces el cuerpo está expuesto a fuerzas sociales y políticas que son las condiciones que hacen posible su subsistencia. Esta apertura, esta dependencia de otros a quienes conocemos pero también y al mismo tiempo de otros a quienes no conocemos y probablemente no conozcamos nunca es la condición de nuestra existencia, pues de alguna forma u otra nuestra vida se encuentra siempre en las manos de los otros.

Sin embargo, esto no significa que todas las vidas sean precarias en el mismo sentido, pues la precaridad está distribuida diferencialmente, lo cual produce vidas que son más vulnerables que otras, es decir, que están más expuestas a la destrucción (y esto de diversas formas, desde la falta de condiciones materiales para subsistir hasta la muerte producida por guerras). La precaridad es aquella condición inducida políticamente, en la cual algunas poblaciones no acceden a redes económicas y sociales de contención y por lo tanto quedan más expuestas a los daños, a la violencia y, en última instancia, a la muerte.

¿Pero cómo se distribuye la precaridad de forma diferente? ¿Podemos leer el marco como participando de la producción de la precariedad, induciendo la precariedad? ${ }^{9} \mathrm{El}$ marco, sostiene Butler, no exhibe simplemente la realidad, sino que la produce de forma activa al seleccionar qué contará como realidad y qué no.

[L]os marcos mediante los cuales aprehendemos, o no conseguimos aprehender, las vidas de los demás como perdidas o dañadas (susceptibles de perderse o de dañarse) están políticamente saturados. Son ambas, de por sí, operaciones del poder. (Butler, 2010c, pp. 13-14)

En este sentido, el marco es una interpretación que determina lo que será incluido o no en el campo de percepción, es un poder que orquestra lo que daremos en llamar "realidad".

Sin embargo, la cuestión no se reduce a la existencia de un discurso que produce los efectos de deshumanización o desrealización, es decir que no hay, actualmente, un discurso que sostenga que determinada subjetividad no cuenta como vida humana o, por lo menos, no es ese el mecanismo primario 
de deshumanización. Es más bien en los límites del discurso, en los límites de la vida discursiva, donde encontramos los silencios y las omisiones que producen aquellos efectos de deshumanización.

En este sentido, si la vulnerabilidad es una condición para la humanización y la humanización tiene lugar de diferentes formas a través de normas variables de reconocimiento, entonces la vulnerabilidad, si es que va a ser atribuida a cualquier sujeto humano, depende fundamentalmente de normas existentes de reconocimiento. (Butler, 2009b, p. 70-71)

Estas normas de reconocimiento, acaso lo que en sus libros anteriores Butler llamó la "matriz de inteligibilidad" y que en su libro Marcos de guerra llama "el marco", delimitan lo que podemos aprehender y lo que no, es decir que no sólo organizan las experiencias (visuales, auditivas, etc.) sino que al mismo tiempo generan ontologías específicas del sujeto. Así, a través de los esquemas normativos que dependen de operaciones más amplias de poder, habrá "sujetos" que no serán reconocibles como sujetos y habrá "vidas" que no serán reconocidas como vidas.

¿Qué nuevas normas son posibles y cómo son producidas? ¿Qué podría hacerse para producir una serie más igualitaria de las condiciones de reconocibilidad? En otras palabras, ¿qué podría hacerse para cambiar los términos mismos de la reconocibilidad con el fin de producir unos resultados más radicalmente democráticos? (Butler, 2010c, p. 20)

Para responder estas preguntas por la posibilidad de producir nuevas condiciones de reconocimiento que sean más igualitarias, se podría retomar la noción de "iteración” y pensar en que dicha estructura iterativa, al repetir las normas en nuevos contextos espaciales y temporales, abre a la transformación de aquellos marcos de reconocimiento. Sin embargo, querría ahora centrarme en la cuestión de las coaliciones políticas para poder vislumbrar nuevas potencialidades de resistencia. Tal como sostiene Butler en el artículo "El no-pensamiento en nombre de lo normativo", las coaliciones políticas no se constituyen en función de una identidad previa o en términos comunes de reconocimiento, sino más bien en función de formas de oposición política a cierto estado y a determinadas políticas regulatorias. En este sentido, las coaliciones no están basadas en posiciones de sujeto y, de hecho, pueden basarse en una superposición de objetivos provisorios. Incluso puede haber antagonismos acerca de los objetivos o de cuál es la mejor manera de alcanzarlos; es decir que puede haber fracturas, quiebres, etc.

En este punto Butler cita a Ernesto Laclau y a Chantal Mouffe y nos remite a Hegemonía y estrategia socialista. Es por eso que daremos un rodeo por esta teoría, para analizar lo que ellos llaman una "democracia radical y plural" y para preguntarnos si hay algo así en la teoría de Judith Butler.

\section{B. Hegemonía y estrategia socialista. Radicalización de la democracia.}

Según sostienen Ernesto Laclau y Chantal Mouffe en Hegemonía y estrategia socialista, en los años setenta la teoría marxista llegó a un punto muerto y el pensamiento de izquierda se encontró en una encrucijada debido, por un lado, a las transformaciones históricas que habían puesto en crisis los fundamentos del marxismo y, por el otro, al surgimiento de los "nuevos movimientos sociales" que extendieron la conflictividad social a diversos terrenos en lugar de anclarla en la lucha de clases.

Lo que está actualmente en crisis es toda una concepción del socialismo fundada en la centralidad ontológica de la clase obrera, en la afirmación de la Revolución como momento fundacional en el tránsito de un tipo de sociedad a otra, y en la ilusión de la posibilidad de una voluntad colectiva perfectamente una y homogénea que tornaría inútil el momento de la política. (Laclau y Mouffe, 2010, p. 26)

Los autores se proponen releer la teoría marxista a la luz de los problemas contemporáneos y deconstruir ciertas categorías centrales del marxismo, como por ejemplo la noción de clase social como unidad de las posiciones del sujeto de los diversos agentes. Así, privilegian el momento de la articulación política y toman como categoría central del análisis político a la hegemonía. Este es, mutatis mutandi, el mismo marco teórico 
propuesto por Michel Foucault que Butler retoma, por lo menos en lo concerniente a la crítica a la idea de la clase social como el agente ya constituido de la revolución y la concepción de la crisis de la Revolución.

En la teoría de Laclau y Mouffe (Laclau y Mouffe, 2010), la articulación es “toda práctica que establece una relación tal entre elementos, que la identidad de éstos resulta modificada como resultado de esa práctica" (Laclau y Mouffe, 2010, pp. 142-143). Dichos elementos (que son diferencias no articuladas discursivamente) se convierten en "momentos", es decir, en posiciones diferenciales, al aparecer articuladas en el interior de un discurso. La formación discursiva constituye una configuración que no se funda en ninguna entidad sustancial o trascendental y que no constituye una totalidad suturada, pues toda identidad es relacional y la fijación de elementos como momentos no puede nunca realizarse completamente. $Y$ es en este punto donde se hace posible la práctica articulatoria, pues si las relaciones y las identidades pierden su carácter necesario, las identidades son puramente relacionales, no hay identidad que logre constituirse plenamente.

En la medida en que toda identidad es relacional, pero el sistema de relación no consigue fijarse en un conjunto estable de diferencias; en la medida en que todo discurso es subvertido por un campo de discursividad que lo desborda; en tal caso la transición de los "elementos" a los "momentos" no puede ser nunca completa. (Laclau y Mouffe, 2010, p. 153)

La incompletitud de toda formación discursiva, sumado a la relacionalidad de toda identidad, permite entrever que el carácter ambiguo del significante (es decir que no está fijado a ningún significado) existe en la medida en que hay una proliferación de significados. Esta polisemia, esta dimensión sobredeterminada, simbólica, de toda formación es la que permite la desarticulación de la estructura discursiva. La práctica de la articulación consistirá, por tanto, en la construcción de puntos nodales que fijarán parcialmente el sentido.

En este campo de las prácticas articulatorias (es decir, un campo donde los elementos no han cristalizado en momentos) es donde podrá emerger la hegemonía. En la teoría de Laclau y Mouffe, la hegemonía supone el carácter incompleto y abierto de lo social, es decir, el campo de las prácticas articulatorias. Una relación hegemónica sólo puede darse gracias a la dimensión de indecidibilidad estructural, en la medida en que elementos que no están predeterminados por su propia naturaleza a entrar en cierto tipo de articulación, sin embargo, se ven configurados de cierta forma. Esta articulación hegemónica va a ser la dimensión central de la política.

¿[C]ómo tiene que ser una relación entre entidades para que una relación hegemónica resulte posible? Su condición inherente es que una fuerza social particular asuma la representación de una totalidad que es radicalmente inconmensurable con ella. (Laclau y Mouffe, 2010, p. 10)

Así, un conjunto de particularidades establece entre sí relaciones de equivalencia, pues hay una necesidad de representar la totalidad de la cadena más allá del particularismo diferencial de los eslabones equivalentes. Una particularidad se divide y, sin dejar de ser particular, transforma su cuerpo en la representación de una universalidad que la trasciende. La relación por la cual cierta particularidad asume la representación de la universalidad enteramente inconmensurable con dicha particularidad es la relación hegemónica. Así, la universalidad es siempre una universalidad contaminada que no puede escapar a la tensión irresoluble entre particularidad y universalidad y cuya función de universalidad hegemónica no es definitiva sino, por el contrario, siempre reversible.

Lo social está marcado por una multiplicidad de antagonismos. Dichos antagonismos no pueden ser ni una oposición real del tipo $\mathrm{A}-\mathrm{B}$, en la que cada término tendría una positividad propia e independiente, ni tampoco una contradicción lógica del tipo A - no A, en la que la relación de cada término con el otro agotaría la realidad de ambos. Tanto la oposición real como la contradicción lógica son relaciones objetivas, es decir, algo que los objetos ya son: identidades plenas. En el antagonismo, por el contrario, la relación no surge de identidades plenas sino de la imposibilidad de constitución de tales identidades. Ni el sí mismo ni la fuerza antagónica son presencias plenas. Así, el antagonismo constituye los límites de toda objetividad, es una relación en la que se muestran los límites de toda objetividad. 
Si el antagonismo cierra toda posibilidad de reconciliación final, la política como esfera pública libre de exclusiones se convertirá en una imposibilidad conceptual. El conflicto y la división no son disturbios que desgraciadamente no pueden ser eliminados ni impedimentos empíricos que imposibilitan la armonía sino que, sin conflicto ni división, una política pluralista y democrática sería imposible.

[E]s vital para la política democrática reconocer que toda forma de consenso es el resultado de una articulación hegemónica, y que siempre existirá una exterioridad que impedirá su realización plena. (Laclau y Mouffe, 2010, p. 18)

Es por eso que, sostienen Laclau y Mouffe, es necesario crear cadenas de equivalencias entre las varias luchas democráticas en contra de las diferentes formas de subordinación. Así, los "nuevos movimientos sociales" (luchas urbanas, ecológicas, antiautoritarias, antiinstitucionales, feministas, antirracistas, de minorías étnicas, regionales o sexuales) encontrarán un denominador común en su diferenciación respecto de las luchas obreras como luchas de clase. Al mismo tiempo, deberán ser articuladas con las luchas de los trabajadores en un nuevo proyecto hegemónico de izquierda.

Y así llegamos al proyecto de una democracia radicalizada y plural, que sólo tendrá lugar si aceptamos que es imposible reconducir las posiciones de sujeto a un principio positivo y fundante de aquéllas.

El pluralismo es radical solamente en la medida en que cada uno de los términos de esa pluralidad de identidades encuentra
en sí mismo el principio de su propia validez, sin que ésta deba ser buscada en un fundamento positivo y trascendente -o
subyacente- que establecería la jerarquía o el sentido de todos ellos, y que sería la fuente y garantía de su legitimidad. Y este
pluralismo radical es democrático, en la medida en que la autoconstructividad de cada uno de sus términos es la resultante de
desplazamientos del imaginario igualitario. (Laclau y Mouffe, 2010, p. 211)

Por eso el proyecto de una democracia radical y plural debe, a los ojos de Laclau y Mouffe, ubicarse dentro del campo de la "revolución democrática". Como analiza Claude Lefort y retoman los autores de Hegemonía y estrategia socialista, la "revolución democrática" es una mutación a nivel simbólico y una nueva institución de lo social. Las sociedades anteriores habrían estado organizadas según una lógica teológico-política en la cual el poder estaba incorporado a la persona del príncipe que era el representante de Dios y es allí donde hallaba su fundamento. En la sociedad democrática, el poder pasa a ser un lugar vacío, en la medida en que desaparece la referencia a una garantía trascendente y, por lo tanto, hay una escisión entre el poder, el saber y la ley, y sus fundamentos ya no están asegurados.

Si consideramos la democracia radical y plural como una etapa en la profundización de la "revolución democrática”, entonces las luchas democráticas por la igualdad y la libertad se extienden a un número creciente de relaciones sociales. Se trata de expandir las cadenas de equivalencias a las distintas luchas contra la opresión.

La tarea de la izquierda no puede por tanto consistir en renegar de la ideologia liberal democrática sino al contrario, en profundizarla y expandirla en la dirección de una democracia radicalizada y plural. (Laclau y Mouffe, 2010, p. 222)

Me he demorado en la exposición de la teoría de la hegemonía de Laclau y Mouffe para llegar a este punto: el proyecto de una democracia radical y plural como nueva forma de resistencia surge luego del fracaso de la Revolución o, nuevamente en palabras de Foucault, de la imposibilidad del lugar del "Gran Rechazo" (Foucault, 2005, p. 116). Ahora volveremos a los desarrollos de Judith Butler para indagar la forma que toma la idea de la resistencia en su teoría y así pensar si ésta puede ser algo más que la iteración de las normas o, más aún, si hay en Butler un proyecto de democracia radical y plural.

\section{En busca de una "democracia radical y plural" en la teoría de Judith Butler}

En su último libro, Cuerpos aliados y lucha politica, Judith Butler analiza las asambleas públicas, sus formas y sus efectos. Para ella, hay una disyunción entre la forma política de la democracia y el principio de la soberanía popular que es menester mantener si queremos entender "cómo las expresiones de la voluntad popular pueden 
poner en cuestión una forma política determinada, en concreto la que se presenta como democrática, aunque sus críticos la pongan en duda." (Butler, 2017, p.10). Pues un orden político considerado democrático puede ser puesto en crisis por un colectivo que se considera la voluntad popular y que representa al pueblo, quizás incluso con la promesa de traer una democracia más real.

Vemos así cómo Butler cambia el foco del análisis y se centra en estas asambleas públicas, en estas expresiones de la voluntad popular, en lugar de poner en el centro de su teoría la ley. El debate se centrará en el sentido de la democracia.

Ahora bien, ¿qué está en juego cuando un grupo o una asamblea o un colectivo orquestado se llama a sí mismo "el pueblo"? ¿Quién es realmente "el pueblo"? Sabemos que no se trata de una población dada, sino que se constituye a través de las líneas de demarcación que se establecen explícita o implícitamente. Así, cuando dicho colectivo determina que es "el pueblo", hace presunciones sobre quién está incluido y quién no. No existe en efecto una asamblea que logre representar la totalidad del pueblo, sino que más bien cada postulación del pueblo a través de la asamblea da lugar a una serie de conflictos acerca de quién es el pueblo.

Así, la determinación de quién pertenece al pueblo precisa de un sector de la población que no pertenezca a ese colectivo. Este "exterior constitutivo" es difícilmente superado y, de hecho, como desarrollamos en el apartado anterior, el cuerpo político postulado como unidad no puede nunca ser tal. Toda formación del "pueblo" necesita una frontera discursiva en algún lado; ésta puede ser trazada a lo largo de las líneas de las naciones-estado, de las comunidades lingüísticas o raciales, o de las afiliaciones políticas. Así, cualquier proclama en nombre del "pueblo" estará dejando fuera a algún grupo.

Esto significa que "el pueblo" nunca aparece en realidad como una presencia colectiva que habla al unísono; sean quienes sean sus integrantes, no cabe duda de que el pueblo está internamente dividido y se hace presente de un modo diferenciado o secuencial, o no aparece en modo alguno o solo en cierta parte, y posiblemente en alguna medida aparece tanto reunido como disperso y, en última instancia, no como una unidad. (Butler, 2017, p. 169)

Esto puede llevar a una conclusión cínica, a saber, que, dado que toda formación del "pueblo" es parcial, entonces la política carece de sentido. Sin embargo, otra actitud es posible: para la estadounidense, se trata de exponer esas formas de exclusión y de oponerse a ellas, aun sabiendo que la inclusión absoluta es imposible, pues la lucha está en curso. Es que para Butler la inclusión no es el único objetivo de la democracia, sino que la política democrática ("especialmente la democracia radical”, sostiene la autora; y volveré sobre este punto) trabaja, justamente, con las inclusiones y las exclusiones. Así, el punto no es extender el reconocimiento de forma igualitaria a todo el mundo, sino comprender que sólo cambiando la relación entre lo reconocible y lo no reconocible se puede entender y perseguir la igualdad y "el pueblo" puede tornarse un concepto abierto, pasible de reelaboración.

[...] esas formas explícitas e implícitas de desigualdad que en ocasiones traducen categorías esenciales como las de inclusión y reconocimiento han de ser abordadas dentro de la lucha democrática que se ha abierto. (Butler, 2017, p. 13)

La operación de poder que se halla tras el problema de la demarcación es performativa, es decir que postularse como "el pueblo" hace mucho más que simplemente nombrar quién es ese pueblo: el acto de delimitación opera de acuerdo con una forma performativa del poder que establece un problema fundamental de la democracia al ofrecer su concepto clave, "el pueblo".

Antes de cualquier debate en el lenguaje acerca de quién es "el pueblo", hay una unión de los cuerpos que habla de otra forma. Estas uniones de los cuerpos, estas asambleas, se reivindican y se representan justamente juntándose en el espacio público, ya sea de forma organizada o espontánea. Un grupo no se une como "el pueblo" a través de un acto de habla puntual, sino que la asamblea ya está hablando mucho antes de que cualquier palabra sea pronunciada: por el mero hecho de juntarse esa multitud de personas está ya representando una voluntad popular" (Butler, 2017, p. 159).

Las asambleas populares tienen una función crítica que está vinculada al hecho de que son transitorias, de que se forman quizás de manera inesperada y se disuelven y pueden cuestionar la legitimidad del gobierno que 
dice representar al pueblo. Una acción colectiva puede ser una forma encarnada de cuestionar las nociones de lo político establecidas y esto funciona a través de asambleas, huelgas, vigilias y la ocupación del espacio público. Pero los cuerpos que llevan a cabo la manifestación parten de la precariedad como su condición, de una precariedad inducida que produce que sus vidas queden al margen de la contención política, económica y social.

[C] uando los cuerpos se congregan en la calle, en una plaza o en otros espacios públicos (virtuales incluidos), están ejercitando un derecho plural y performativo a la aparición, un derecho que afirma e instala el cuerpo en medio del campo político, y que, amparándose en su función expresiva y significante, reclaman para el cuerpo [delivers a bodily demand] condiciones económicas, sociales y políticas que hagan la vida más digna, más vivible, de manera que esta ya no se vea afectada por las formas de precariedad impuestas [induced forms of precarity]. (Butler, 2017, p. 18)

Si bien todos somos precarios, y esto se sigue de nuestra existencia social como cuerpos que dependen el uno del otro para subsistir, nuestra precariedad depende en gran medida de la organización de las relaciones económicas y sociales, de la presencia o de la ausencia de infraestructuras y de instituciones sociales y políticas. Así, la precariedad es indisociable de la dimensión política que organiza y protege nuestras necesidades. Como señala Isabell Lorey (Lorey, 2016), la precarización es inducida y reproducida por instituciones gubernamentales y económicas, y esto acostumbra a las poblaciones a vivir en la inseguridad y la desesperanza (Lorey, 2016, pp.17-30).

Sin embargo, encontrarse en situaciones de exposición radical a la violencia o sin la protección política básica no significa que se esté afuera de la política o privado de toda forma de agencia. Estando fuera de las estructuras políticas se está igualmente saturado de relaciones de poder y esta saturación es justamente el punto de partida de una teoría de lo político que incluye las formas dominantes y subyugadas, los modos de inclusión y de legitimación, así como los modos de deslegitimación e invisibilización. Así, es posible pensar la vulnerabilidad como una forma de activismo o, mejor dicho, como aquello que en algún sentido puede movilizar formas de resistencia, pues las poblaciones o los grupos sociales que están marcados de forma diferencial por la vulnerabilidad o la precariedad no quedan por esa razón paralizados. Por el contrario, cuando emergen luchas políticas en contra de tales condiciones, están movilizando la precariedad.

Cuando los cuerpos se reúnen en la calle, en la plaza o en algún otro espacio público, están ejerciendo performativamente su "derecho a aparecer" (Arendt, 2009, pp. 222-230), están haciendo una demanda corporal por vidas más vivibles. La demanda de derechos colectivos emerge de una comprensión, por lo menos incipiente, de que la situación de precariedad que esas personas viven es compartida, de que la precariedad está distribuida de forma diferencial y que la forma de resistir debe basarse en la demanda de que esas vidas deberían ser tratadas de forma igualitaria y deberían ser igualmente vivibles.

Muchas veces la precariedad opera como el sitio de alianza entre grupos de personas que, de otra forma, no tendrían mucho en común o que incluso podrían tener relaciones antagónicas. A los ojos de Butler, y esta idea viene ya siendo expresada desde El género en disputa, la política de la identidad o la ontología identitaria no es suficiente para dar cuenta del problema de las alianzas políticas. Cuando los cuerpos se juntan para expresar su indignación y para manifestar su existencia plural en el espacio público, están manifestándose por demandas más amplias: por el reconocimiento, por la valoración, por el derecho a aparecer, por el derecho a ejercer su libertad, por una vida vivible. No importa sobre qué versa una protesta, siempre es, al mismo tiempo, una demanda por el derecho a reunirse, a constituir asambleas, pues esas representaciones plurales ponen de manifiesto que la situación de precariedad es compartida

La aparición, el quedarse parado, la respiración, el movimiento, el detenerse, el habla y el silencio son todos elementos que forman parte de una asamblea imprevista, de una forma inesperada de la performatividad política que sitúa la vida vivible en el primer plano de la política. Y es lo que parece estar ocurriendo antes de que el grupo en cuestión exponga sus demandas o empiece a explicarse con un discurso político apropiado. (Butler, 2017, p. 25) 
Más allá de la demanda concreta, lo que vemos en estos encuentros públicos son cuerpos que "dicen" de una forma $u$ otra que no son desechables, que están presentes. Piden reconocimiento, pero para obtener ese reconocimiento es necesario encarnar la(s) norma(s) de reconocimiento. Si ciertos cuerpos "ininteligibles" conforman un grupo y desarrollan formas para volverse "inteligibles", es porque están existiendo y persistiendo en los límites de las normas establecidas.

[A] veces lo más importante no es el poder que uno tiene y que le faculta para actuar, a veces, lo que hay que hacer es actuar, y a partir de esa actuación reclamar el poder que uno necesita. Así es como yo entiendo la performatividad, y esta es también una de las formas de actuar contra y desde la precariedad [precarity]. (Butler, 2017, p. 63)

Aquí la propuesta butleriana radica en esforzarse por encontrar modos de vida en los cuales los actos performativos luchen contra la precariedad, es decir, una lucha que busque abrir un futuro en el que podamos vivir nuevas formas sociales de existencia. Se trata aquí de una acción colectiva que no cuenta con un sujeto colectivo pre-establecido, sino que se constituye en el encuentro de los cuerpos, un "nosotros" plural, persistente, que actúa, que le reclama a una esfera pública que lo ha abandonado.

Si estar excluido de los espacios de aparición es estar excluido de la pluralidad que da existencia al espacio de aparición, entonces es estar privado del derecho a tener derechos. Por eso la acción plural y pública es el ejercicio del derecho a pertenecer. "Actuar en nombre de ese apoyo pero sin contar con é les la paradoja de la acción performativa plural que tiene lugar bajo las condiciones de precariedad [precarity].” (Butler, 2017, p. 70)

Así, se trata de encontrar una nueva política que comienza con una comprensión de la dependencia y de la interdependencia humana y que puede dar cuenta de la relación entre precariedad y performatividad. Resistir será acaso producir nuevas formas de vida, vidas más vivibles que se opongan a la distribución diferencial de la precariedad.

$[\mathrm{L}] \mathrm{a}$ acción coordinada que caracteriza a la resistencia se encuentra a veces en los actos verbales del habla o de las luchas heroicas, pero también podemos verla en esos gestos del cuerpo que indican rechazo, silencio, movimiento e inmovilidad deliberada y que son rasgos característicos de todos esos movimientos que ponen en marcha los principios democráticos de la igualdad y los principios económicos de interdependencia en una misma acción, en aquella por medio de la cual hacen un llamamiento a la adopción de un nuevo modo de vida que sea más radicalmente democrático y más independiente. (Butler, 2017, p. 218)

Así, cuando un movimiento social busca una nueva forma de vida o una forma de vida más vivible, hay una puesta en acto performativa de democracia radical. En una lucha contra la precariedad, no se trata de superar la interdependencia o la vulnerabilidad sino de producir condiciones bajo las cuales la interdependencia y la vulnerabilidad se tornen vivibles.

\section{Conclusiones}

Comencé el artículo indagando la capacidad de agencia y la posibilidad de resistencia en el marco teórico deconstructivo de Judith Butler. Así, me pregunté si era posible transformar aquellas relaciones de poder que, justamente, nos constituyen y esto me llevó al análisis de la noción de "subversión" que Butler desarrolla en sus primeros libros, El género en disputa, cuerpos que importan, Lenguaje, poder e identidad y Mecanismos psiquicos del poder. Allí, la resistencia es pensada en términos de la constitución de la subjetividad y de la capacidad de agencia de los sujetos. En ese sentido, la resistencia está en la encrucijada de la iteración en su doble acepción de repetición y resignificación y la capacidad de agencia, lejos de ser un atributo de las personas en tanto que tales, pasa a ser una práctica de rearticulación al interior de las relaciones de poder.

Siguiendo los desarrollos de Butler, la introducción de la problemática de la precari(e)dad lleva a repensar, dentro del marco conceptual ya expuesto, las estrategias de resistencia en democracia. Al vincular la precariedad con la performatividad en su último libro, Cuerpos aliados y lucha politica, Butler analiza las 
manifestaciones en el espacio público y reflexiona sobre las formas de aparición en dicho espacio. Si se parte de la precariedad como condición socio-ontológica que a su vez está distribuida diferencialmente entre la población, se puede pensar las constituciones asamblearias como procesos de resistencia política que, a través de la articulación de la precariedad, se proponen la inclusión en las instituciones democráticas. A su vez, esta inclusión indefectiblemente transforma dichas instituciones y esto se constituye o por lo menos tiene la potencialidad de constituirse en un cuestionamiento de las nociones establecidas de lo político.

Estos análisis me llevaron a preguntarme si hay en la teoría butleriana algo así como una "democracia radical y plural", en el sentido en que la delinearon Ernesto Laclau y Chantal Mouffe, y creo que se puede dar una respuesta afirmativa, si se contempla que las asambleas analizadas por Butler pueden ser leídas como articulaciones en el marco de los antagonismos del espacio social que buscan una distribución de la precariedad un poco menos desigual, de forma tal que los soportes económicos, políticos, sociales y culturales permitan vidas más vivibles.

Así, la noción de "resistencia", tan fundamental en los tiempos actuales, tanto a nivel teórico (para poder dar una respuesta a la crítica que sostiene que si el sujeto no es pensado como autónomo, voluntario y libre entonces pierde toda capacidad de agencia) como a nivel político (en términos del neoliberalismo y sus condiciones políticas, económicas, sociales y culturales y la necesidad de luchar por una mejor distribución de la precari(e)dad), puede ser pensada desde varias aristas en Judith Butler. Sin que se trate de una progresión en términos de evolución de su pensamiento, podemos delinear determinadas transformaciones en la obra de Butler que abren a la reflexión de problemáticas contemporáneas, precisamente porque ella desarrolla su teoría en función de determinadas problemáticas localizadas espacio-temporalmente. En este sentido, considero que su concepción de la resistencia, tanto a nivel de la constitución de subjetividades, como en términos de la constitución de las asambleas políticas, es decir, la resistencia pensada en términos de vulnerabilidad y performatividad, es un vector a través del cual podemos repensar problemáticas actuales en busca de un proyecto de democracia radical y plural. ${ }^{10}$

\section{Bibliografia}

Arendt, Hannah (2009) "El poder y el espacio de aparición”, en La condición humana. Buenos Aires: Paidós.

Butler, Judith (2001) “Fundamentos contingentes: el feminismo y la cuestión del 'postmodernismo', en La Ventana, núm. 13, trad. M. Silva, Universidad de Guadalajara.

Butler, Judith (2007) El género en disputa. El feminismo y la subversión de la identidad. Barcelona: Paidós.

Butler, Judith (2009a) Lenguaje, poder e identidad. Madrid: Síntesis.

Butler, Judith (2009b) Vida precaria. El poder del duelo y la violencia. Buenos Aires: Paidós.

Butler, Judith (2010a) Cuerpos que importan. Sobre los límites materiales y discursivos del "sexo". Buenos Aires: Paidós.

Butler, Judith (2010b) Mecanismos psíquicos del poder. Teorias sobre la sujeción. Madrid: Cátedra.

Butler, Judith (2010c) Marcos de Guerra. Las vidas lloradas. Mexico: Verso: Paidós.

Butler, Judith (2017) Cuerpos aliados y lucha politica. Hacia una teoría performativa de la asamblea. Buenos Aires: Paidós.

Cragnolini, Mónica (comp.) (2005) Modos de lo extraño: alteridad y subjetividad en el pensamiento postnietzscheano. Buenos Aires: Santiago Arcos Editor

Feministische Studien (1993) "Kritik der Kategorie "Geschlecht", 11. Jg., Nr. 2.

Foucault, Michel (2005), Historia de la sexualidad I. La voluntad de saber. Buenos Aires: Siglo XXI Editores.

Heidegger, Martin (2005) "La época de la imagen del mundo", en Caminos de Bosque, trad. H. Cortés y A. Leyte, Madrid, Alianza.

Laclau, Ernesto y Mouffe, Chantal (2010) Hegemonía y estrategia socialista: hacia una radicalización de la democracia. Buenos Aires: Fondo de Cultura Económica. 
Lorey, Isabell (2016) Estado de inseguridad. Gobernar la precariedad. Madrid: Traficantes de sueños.

Nijensohn, Malena (2013) "Sujetos sin sustancia. De la crítica a la metafísica de la sustancia de Nietzsche a la producción de subjetividades sexo-generizadas de Butler”, en Femenías, María Luis, Cano, Virginia y Torricella, Paula (comps.) (2013) Judith Butler, su filosofia a debate, Buenos Aires: editorial de la Facultad de Filosofía y Letras Universidad de Buenos Aires, pp. 19-49.

Nijensohn, Malena (2015) "Política y feminismo o sobre cómo se llega a ser lo que (no) se es. Una lectura cruzada de las filosofías de Friedrich Nietzsche y Judith Butler”, en Instantes y Azares. Escrituras nietzscheanas, Año XV, Nros. 15-16, Otoño-primavera de 2015, ed. La Cebra, pp. 113-126.

Preciado, Paul B. (2014) Testo Yonqui. Sexo, drogas y biopolitica. Buenos Aires: Paidós.

Sabsay, Leticia (2005) "Políticas de lo performativo: lenguaje, teoría queer y subjetividad", en III Jornadas de Jóvenes investigadores. Instituto Gino Germani, FSOC, Buenos Aires, 29 y 30 de Septiembre.

Wittig, Monique (2006) El pensamiento heterosexual y otros ensayos. Madrid: Egales.

\section{Notas}

1 Cfr. Butler (Butler, 2001), donde la autora cuestiona que exista algo así como la "postmodernidad”, en la medida en que es un término bajo el cual se ha agrupado a un cierto número de posiciones que no son necesariamente iguales. "Un cierto número de posiciones se le adscriben al postmodernismo, como si fuera el tipo de cosa que pudiera ser la portadora de un conjunto de posiciones: el discurso es todo lo que existe, como si el discurso fuera algún tipo de materia monística de la cual todas las cosas se componen; el sujeto está muerto, yo nunca puedo volver a decir "yo"; no existe una realidad, sólo representaciones. Estas caracterizaciones son imputadas muchas veces al postmodernismo o al postestructuralismo, que son mezclados entre sí y a veces mezclados con la deconstrucción, y a veces entendidos como un ensamblaje indiscriminado de feminismo francés, la deconstrucción, el psicoanálisis lacaniano, el análisis foucaultiano, el conversacionalismo de Rorty y los estudios culturales." (p. 10)

2 Prefiero utilizar el término "post-nietzscheano", para señalar aquellas filosofías que son herederas de la "muerte de Dios" o, en otras palabras, de la crítica a la metafísica de la sustancia y que se adentran en el perspectivismo propuesto por tal autor. Como señala Cragnolini (Cragnolini, 2005): "El perspectivismo es un modo de filosofar que 'arriesga', un pensar en posibilidades [...]. El pensar que arriesga es aquel que se constituye en el abismo de la des-fundamentación, aquel que sabe que los viejos dioses han muerto hace tiempo, y que no hay retorno al origen. El pensar que arriesga es el que sabe que estamos en un tiempo de "entre", de oscilación, de temblor. Y que allí, en ese lugar inseguro, en esa ausencia de morada definitiva, es necesario entramar la arquitectura del concepto.” (p. 5)

3 Por ejemplo, el feminismo alemán fue, a principios de los años noventa, muy reacio a aceptar la crítica butleriana a las "mujeres" como sujeto del feminismo. Cfr. Feministische Studien. Kritik der Kategorie "Geschlecht" (1993, 2) en particular, Duden (1993, 2), “Die Frau ohne Unterleib: Zu Judith Butlers Entkörperung. Ein Zeitdokumen” (pp. 24-33), donde la autora sostiene que la deconstrucción es un "baño corrosivo" ("Ätzbad"), en el cual cuerpo, sujeto y mujeres pueden desaparecer (p. 31).

4 Considero menester aclarar que, si bien en cada iteración se abre un espacio de resignificación, esto no significa sin embargo que en cada citación de la norma se la esté subvirtiendo. Muy por el contrario, la mayoría de las veces la reforzamos. Lo que quisiéramos señalar es que es la estructura misma de la iteración la que ofrece la posibilidad de su propia modificación, sin que esto signifique una concreción material de dicho potencial en cada caso.

5 Esto no significa de ninguna forma que Butler sea la primera en formular la crítica al "sujeto del feminismo" como mujer blanca heterosexual de clase media. Por el contrario, Butler se pliega a una serie de críticas que movimientos feministas disidentes (chicano, gay, lésbico, queer, negro, etc.) venían señalando ya desde los años setenta y ochenta. En palabras de Paul B. Preciado (Preciado, 2014): "el nuevo feminismo que emerge a finales de los años ochenta de la mano de Gayle Rubin, Judith Butler o Teresa de Lauretis, no deja de inventar imaginarios políticos y de crear estrategias de acción que ponen en cuestión aquello que parece más obvio: que el sujeto político del feminismo sean las mujeres. Es decir, las mujeres entendidas como una realidad biológica predefinida, pero, sobre todo, las mujeres como deben ser, blancas, heterosexuales, sumisas y de clase media. Emergen de este cuestionamiento nuevos feminismos de multitudes, feminismos para los monstruos, proyectos de transformación colectiva para el siglo XXI. Estos feminismos disidentes se hacen visibles a partir de los años ochenta, cuando, en sucesivas oleadas críticas, los sujetos excluidos por el feminismo biempensante comienzan a criticar los procesos de purificación y la represión de sus proyectos revolucionarios que ha conducido hasta un feminismo gris, normativo y puritano que ve en las diferencias culturales, sexuales o políticas amenazas a su ideal heterosexual y eurocéntrico de mujer. Se trata de lo que podríamos llamar, tomando la expresión de 
Virginie Despentes, el despertar crítico del 'proletariado del feminismo', cuyos malos sujetos son las putas, las lesbianas, las violadas, los cis-hombres disidentes, las marimachos, los y las transexuales, las mujeres que no son blancas, las musulmanas..., en definitiva, casi todos nosotros." (p. 263)

6 Sobre la relación entre las filosofías de Friedrich Nietzsche y de Judith Butler, ver: Nijensohn (Nijensohn, 2013) y Nijensohn (Nijensohn, 2015).

7 Cfr. Butler, 2009a, p. 50: "El acto de reconocimiento se convierte en un acto de constitución: la llamada trae el sujeto a la existencia."

8 La crítica al sujeto como "subjectum" puede encontrarse en: Heidegger (2005), donde este autor desarrolla la constitución del sujeto moderno como la transformación del hombre en subjectum, al tiempo que el mundo se convierte en objectum. El hombre, enfrentado con el mundo, reúne todo lo que yace ante él sobre sí, convirtiendo al mundo en imagen re-presentada, es decir, traída ante sí, referida a sí. El hombre se posiciona como la escena en la cual lo ente se representa. La constitución del sujeto como subjectum es el proceso por el cual el sujeto se transforma en hypokhéimenon, es decir, en el fundamento o, en palabras heideggerianas, en el "centro de referencia de lo ente como tal" (Heidegger, 2005, p. 72)

9 Cfr: Butler, 2010b, pp. 16-17. "De esta manera, la producción normativa de la ontología produce el problema epistemológico de aprehender una vida, lo que, a su vez, da origen al problema ética de saber qué hay que reconocer, o, más bien, qué hay que guardar contra la lesión y la violencia. [...] Los 'marcos' que operan para diferenciar las vidas que podemos aprehender de las que no podemos aprehender (o que producen vidas a través de todo un contínuum de vida) no sólo organizan una experiencia visual, sino que, también, generan ontologías específicas del sujeto."

$10 \mathrm{Al}$ respecto, el caso de las movilizaciones masivas y el proceso asambleario del movimiento feminista en Argentina a partir de 2015 es ilustrativo y tema de una investigación futura. 